\title{
Correlation between mechanical properties and stabilization time of chemical bonds in glass-ionomer cements
}

\section{Rafael MENEZES-SILVA ${ }^{(a)}$ \\ Bruna Medeiros Bertol de OLIVEIRA $^{(b)}$ iD \\ Ana Paula Rodrigues \\ MAGALHÃES(c) ID \\ Lígia Saraiva BUENO(a) iD \\ Ana Flávia Sanches BORGES(a) iD \\ Mauro Luciano BAESSO(d) ID \\ Maria Fidela de Lima \\ NAVARRO $^{(a)}$ \\ John Willian NICHOLSON(e) \\ Sharanbir Kaur SIDHU(e) \\ Renata Corrêa PASCOTTO(b)}

(a) Universidade de São Paulo - USP, Bauru

School of Dentistry, Department of

Operative Dentistry, Endondontics and

Dental Materials, Bauru, SP, Brazil.

(b) Universidade Estadual de Maringá - UEM,

Department of Dentistry, Maringá, PR, Brazil.

(c) Universidade Paulista - UNIP, Dentistry School, Department of Dentistry, Goiânia, Goiás, Brazil.

(d) Universidade Estadual de Maringá - UEM, Department of Physics, Maringá, PR, Brazil.

(e) Queen Mary University of London, The London School of Medicine and Dentistry,

Institute of Dentistry, Barts \&amp, London, UK.

Declaration of Interests: The authors certify that they have no commercial or associative interest that represents a conflict of interest in connection with the manuscript.

Corresponding Author:

Renata Corrrêa Pascotto

E-mail: renatapascotto@gmail.com

ht1ps://doi.org/10.1590/1807-3107bor-2020.vol34.0053

Submitted: December 6, 2019

Accepted for publication: April 20, 2020

Last revision: April 29, 2020
Abstract: The objective was to evaluate the compressive strength (CS), diametral tensile strength (DTS), flexural strength (FS), and Knoop microhardness $(\mathrm{KH})$ of different conventional restorative glass-ionomer cements (GICs) and to correlate these mechanical properties (MP) with the stabilization time (ST) of their chemical bonds. Eighteen GICs were tested: Bioglass [B], Chemfil Rock [CR], Equia Forte [EF], Gold Label 2 [GL2], Gold Label 9 [GL9], Glass Ionomer Cement II [GI], Ionglass [IG], Ion Z[ IZ], Ionomaster [IM], Ionofil Plus [IP], Ionostar Plus [IS], Ketac Molar Easymix [KM], Magic Glass [MG], Maxxion R [Ma], Riva Self Cure [R], Vidrion R [V], Vitro Fil [VF] and Vitro Molar [VM]. The mechanical strength tests were performed in a universal testing machine. $\mathrm{KH}$ readings were done with a diamond indenter. STs were examined by Fourier Transform Infrared spectroscopy (FTIR). Data were analyzed with ANOVA and Tukey test $(\mathrm{p}<0.05)$. The Spearman rank test was used to evaluate the dependence between the MPs and ST results. The highest MP values were EF, GL2, GL9, GI and KM and the lowest for MG, MA, B, VF and IM. The longest ST was for GL2 and the shortest was for B. ST correlated positively with MP. GICs with longer chemical bonds ST are generally stronger and the ST value obtained from FTIR was useful in predicting the strength of GICs tested.

Keywords: Glass Ionomer Cements; Compressive Strength; Flexural Strength; Spectroscopy, Fourier Transform Infrared.

\section{Introduction}

Glass-ionomer cement (GIC) is a water-based material that slowly hardens following an acid-base reaction between fluoroaluminosilicate glass powder and an aqueous solution of polyacid. ${ }^{1}$ The setting reaction in GICs is a continuous process evident by the increase in mechanical properties of the cement with aging time. ${ }^{2}$

Mickenautsch ${ }^{3}$ analyzed the state of the art of direct restorations in posterior permanent teeth using high viscosity GICs, and concluded that, when used in atraumatic restorative treatment (ART) restorations, they presented a clinical performance similar to amalgam restorations. Gurgan et al. ${ }^{4}$ compared high-viscosity GIC restorations with composite resins on posterior permanent teeth, and observed that restorations achieved similar and successful performance after 6 years. 
Although results such as these encourage the use of GICs, the number of brands available on the market makes it difficult to select a material for use. Variations in the powder/liquid (P/L) ratio, liquid viscosity, composition, and mixing technique may result in very different properties for these cements. ${ }^{5}$.

Moreover, the literature still lacks studies that report the stabilization time of chemical bonds in GICs. Yamakami et al. ${ }^{6}$ recently proposed to analyze the dynamics of GIC setting mechanism based on the time intervals required for the GIC to achieve stability. The setting time or hardening time (in minutes) of a material presented in the package by the manufacturer is different from the time to reach complete reaction or chemical bonds stability (stabilization time) ${ }^{6}$. From the clinical point of view, this information is important because the time for stabilization of chemical bonds can influence mechanical properties of GICs and restoration longevity. Otherwise, much of the work on the maturation changes was carried out several years ago using some earliest versions of GICs. ${ }^{7}$ It is very important to determine how quick the maturation changes take place in modern cements. ${ }^{8}$

The purpose of this study was to compare 18 brands of conventional restorative GICs for their compressive strength, diametral tensile strength, microhardness and flexural strength, and to correlate these properties with the dynamics of their setting process. The null hypotheses evaluated were:

a. there is no difference among the conventional restorative GICs tested in terms of their mechanical properties

b. there is no correlation between mechanical properties and the time interval necessary for the chemical bonds to be formed and stabilized during the setting process in different restorative glass-ionomer cements.

\section{Methodology}

\section{Materials and compositions}

The brands, compositions and powder/liquid ratio $(\mathrm{P} / \mathrm{L})$ of GICs are described in Table 1 . For those materials that did not present the $\mathrm{P} / \mathrm{L}$ ratio in the instructions, the volume of powder and liquid recommended by the manufacturer was weighed 3 times and the arithmetic mean was calculated and adopted as the ideal $\mathrm{P} / \mathrm{L}$ ratio.

The experimental design including the sample size for mechanical tests were done according to the ISO 9917-1:20077 for compressive strength and to the ISO 9917-2:201011, for flexural strength. Anusavice $^{8}$ and ABNT NBR 7222:2011 ${ }^{9}$ were used as reference for diametral tensile strength; Xie et al., ${ }^{10}$ for Microhardness measurements and Yamakami et al., ${ }^{6}$ for dynamic of setting time.

\section{Compressive strength (CS)}

Specimens $(n=5)$ of each material group were prepared using a split steel mold with internal dimensions of $6 \mathrm{~mm}$ high and $4 \mathrm{~mm}$ diameter ${ }^{7}$. Immediately after each cement's manipulation according to the manufacturers instructions, the material was packed with excess into the mold using a syringe, in order to avoid trapping air. On both sides of the mold, polyester strips were placed and the material was compressed using two steel plates and a screw clamp. These procedures were carried out in no longer than 120 seconds.

The whole assembly was stored at $37^{\circ} \mathrm{C}$ and a relative humidity of at least $90 \%$, for $1 \mathrm{~h}$. Then, any excess cement was removed by polishing both sides of the mold with 400-grit silicon carbide paper under continuous water irrigation. The cement specimens were carefully removed from the molds and stored in distilled water at $37^{\circ} \mathrm{C}$ for a further $23 \mathrm{hrs}$.

Finally, the specimens from each group were subjected to the CS test in a universal testing machine (Kratos equipments, K5000, Cotia, Brazil) with a $200 \mathrm{KgF}$ load cell. The specimens were covered with a sheet of damp filter paper on both the top and bottom sides that were contacting with the machine platens. The test was conducted under $0.75 \mathrm{~mm} / \mathrm{min}$ speed, parallel to the specimen's axis, until fracture occurred ${ }^{7}$. The maximum force applied, in $\mathrm{N}$, was used to calculate the CS, in $\mathrm{MPa}$, using the equation:

$\mathrm{C}=4 \mathrm{p} / \pi \mathrm{d}^{2}$;

where $\mathrm{p}$ is the maximum force applied, in Newtons; $\mathrm{d}$ is the measured diameter of the specimens, in millimeters.

According to ISO 9917-1: 2007,7 for compressive strength testing, 5 specimens of each GIC must be performed. If at least four of the five results are 
Table 1. Brands, code, batch numbers, composition and powder/liquid ratio of conventional restorative glass-ionomer cements tested

\begin{tabular}{|c|c|c|c|c|c|}
\hline Material (Manufacturer) & Code & & itch no. & Composition & $\begin{array}{l}\text { Powder / } \\
\text { liquid ratic }\end{array}$ \\
\hline \multirow[t]{2}{*}{ Bioglass R (Biodinâmica, Ibiporã, Brazil) } & \multirow[t]{2}{*}{ B } & & $974 / 15$ & $\begin{array}{c}\text { Calcium, Barium and Aluminum Fluorosilicate, PA } \\
\text { and Inorganic Filler. }\end{array}$ & \multirow[t]{2}{*}{$1.6: 1$} \\
\hline & & Liquid: & & PA, TA and Water & \\
\hline $\begin{array}{l}\text { Chemfil Rock (Dentsply, Milford, } \\
\text { United States) }\end{array}$ & CR & $\begin{array}{l}\text { Powder: } \\
\text { Liquid: }\end{array}$ & 1511000724 & $\begin{array}{l}\text { Zinc-modified fluoro-alumino-silicate glass } \\
\text { PA and itaconic acid }\end{array}$ & capsules \\
\hline $\begin{array}{l}\text { Equia Forte (GC Corporation, } \\
\text { Tokyo, Japan) }\end{array}$ & $\mathrm{EF}$ & $\begin{array}{l}\text { Powder: } \\
\text { Liquid: }\end{array}$ & 1608181 & $\begin{array}{c}\text { Fluoro-alumino-silicate glass, PA powder, Pigment } \\
\text { PA, Distilled water, Polybasic carboxylic acid }\end{array}$ & capsules \\
\hline \multirow{2}{*}{$\begin{array}{l}\text { Gold Label } 2 \text { (GC Corporation, } \\
\text { Tokyo, Japan) }\end{array}$} & \multirow{2}{*}{ GL2 } & Powder: & 1601161 & Fluoro-alumino-silicate glass and PA powder & \multirow{2}{*}{$2.7: 1$} \\
\hline & & Liquid: & 1601121 & Distilled water and PA & \\
\hline \multirow{2}{*}{$\begin{array}{l}\text { Gold Label } 9 \text { (GC Corporation, } \\
\text { Tokyo, Japan) }\end{array}$} & \multirow{2}{*}{ GL9 } & Powder: & 1506021 & Fluoro-alumino-silicate glass, PA powder & \multirow{2}{*}{$3.6: 1$} \\
\hline & & Liquid: & 1506011 & PA, polybasic carboxylic acid & \\
\hline \multirow{2}{*}{$\begin{array}{l}\text { Glass lonomer Cement Type II (Shofu } \\
\text { Inc., Kyoto, Japan) }\end{array}$} & \multirow[b]{2}{*}{$\mathrm{Gl}$} & Powder: & 6144 & Fluoro-alumino-silicate glass & \multirow[b]{2}{*}{$2.5: 1$} \\
\hline & & Liquid: & 31513 & $\begin{array}{c}\text { Copolymer of acrylic acid and tricarboxylic acid, } \\
\text { TA and others }\end{array}$ & \\
\hline \multirow{2}{*}{$\begin{array}{l}\text { longlass (Maquira Dental Products, } \\
\text { Maringá, Brazil) }\end{array}$} & \multirow[t]{2}{*}{ IG } & & 130417 & $\begin{array}{l}\text { PA and sodium fluorosilicate, calcium and } \\
\text { aluminium }\end{array}$ & \multirow[t]{2}{*}{$1.5: 1$} \\
\hline & & Liquid: & & TA and purified water & \\
\hline \multirow{2}{*}{ Ion Z (FGM, Joinville, Brazil) } & \multirow{2}{*}{ IZ } & Powder: & 140116 & Fluoro-alumino-silicate glass & \multirow{2}{*}{$1.7: 1$} \\
\hline & & Liquid: & 130116 & PA and TA & \\
\hline \multirow[t]{2}{*}{ lonomaster (Wilcos, Petrópolis, Brazil) } & \multirow[t]{2}{*}{ IM } & Powder: & 15336 & $\begin{array}{l}\text { Calcium Fluoro-alumino-silicate glass powder, } \\
\text { tartaric acid, citric acid, pigments }\end{array}$ & \multirow[t]{2}{*}{$3: 1$} \\
\hline & & Liquid: & 15335 & Water, PA, pigments & \\
\hline \multirow{2}{*}{$\begin{array}{l}\text { lonofil Plus (VOCO GmbH, } \\
\text { Cuxhaven, Germany) }\end{array}$} & $\mid P$ & Powder: & 1509454 & Fluoro-alumino-silicate glass and PA & 47.56 .1 \\
\hline & & Liquid: & 1506325 & TA & $4.7-5.0: 1$ \\
\hline $\begin{array}{l}\text { lonostar Plus (VOCO GmbH, } \\
\text { Cuxhaven, Germany) }\end{array}$ & IS & $\begin{array}{l}\text { Powder: } \\
\text { Liquid: }\end{array}$ & 1607068 & $\begin{array}{l}\text { Fluoro-alumino-silicate glass, PA, TA } \\
\text { PA solution }\end{array}$ & capsules \\
\hline Ketac Molar Easymix (3M ESPE, & KM & Powder: & 627356 & $\begin{array}{l}\text { Al-Ca-La fluorosilicate glass, copolymer acid } \\
\text { (acrylic and maleic acid) }\end{array}$ & $4.5: 1$ \\
\hline & & Liquid: & 624889 & PA,TA, water & \\
\hline $\begin{array}{l}\text { Magic Glass (Vigodent, Rio de } \\
\text { Janeiro, Brazil) }\end{array}$ & MG & & 1503044 & $\begin{array}{c}\text { Strontium, aluminum, fluoride, silicate, PA, TA and } \\
\text { pigments }\end{array}$ & $2.7: 1$ \\
\hline & & Liquid: & 1401244 & PA, water & \\
\hline Marxinn R (FGM Loinville Brazil) & MA & Powder: & 21117 & Fluoro-alumino-silicate glass, & 5.1 \\
\hline 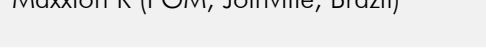 & & Liquid: & 260917 & PA, calcium fluoride, water & \\
\hline Riva (SDI Victoria Australia) & $\mathrm{R}$ & Powder: & $150630 V$ & Glass powder and Acrylic acid polymers & $3 \cdot 1$ \\
\hline Riva (SDI, Victoria, Australia) & $R$ & Liquid: & 15312 & Acrylic acid polymers and TA & $3: 1$ \\
\hline $\begin{array}{l}\text { Vidrion R (SS White, Rio de } \\
\text { Janeiro, Brazil) }\end{array}$ & V & & 220716 & $\begin{array}{l}\text { Sodium fluor silicate, calcium, aluminum, barium } \\
\text { sulphate, PA, pigments. }\end{array}$ & 5.8:1 \\
\hline & & Liquid: & & TA, water & \\
\hline Vitro Fil (Nova DFL, Rio de Janeiro, & VF & Powder: & 16030374 & $\begin{array}{l}\text { Fluorine Strontium Aluminum Silicate, Dehydrated } \\
\text { Polyacrylic Acid and Iron Oxide }\end{array}$ & $2: 1$ \\
\hline & & Liquid: & 16030373 & PA, TA and Distilled Water & \\
\hline Vitro Molar (Nova DFL, Rio de & VM & Powder: & 16020279 & $\begin{array}{c}\text { Fluorine Barium Aluminum Silicate, Dehydrated PA } \\
\text { and Iron Oxide }\end{array}$ & $2.9: 1$ \\
\hline & & Liquid: & 16020278 & PA, Tartaric Acid and Distilled Water & \\
\hline
\end{tabular}

PA: polyacrylic acid; TA: tartaric acid. 
above the minimum strength specified (100 MPa), the material shall pass the test. If three or more of the five results obtained are below the minimum strength, the material shall fail the test. If only three specimens satisfy the minimum strength requirement $(100 \mathrm{MPa})$, it will necessary to prepare and test a further five specimens. To pass the test, at least eight of the total of ten results shall be above the minimum strength value specified for restorative glass-ionomer cement.

\section{Diametral tensile strength (DTS)}

Specimens $(n=5)$ of each group were prepared using a split steel mold with internal dimensions of $3 \mathrm{~mm}$ thick and $6 \mathrm{~mm}$ in diameter. ${ }^{8,9}$ Cement manipulation, insertion in the mold and clamp, storage and excess removal were carried out according to the previous description for CS.

After storage in distilled water at $37^{\circ} \mathrm{C}$ for $23 \mathrm{hrs,}$ the specimens of each group were subjected to the DTS test in a universal testing machine (Kratos Equipments, K5000, Cotia, Brazil) with a $200 \mathrm{KgF}$ load cell. Each specimen was covered with a sheet of damp filter paper on both the top and bottom sides that were contacting with the machine platens. The test was conducted under $0.5 \mathrm{~mm} / \mathrm{min}$ speed, applying stress on the specimen's diameter, until fracture occurred. ${ }^{8,9}$ The maximum force applied in $\mathrm{N}$, was used to calculate the DTS, in $\mathrm{MPa}$, using the equation:

$\mathrm{DTS}=2 \mathrm{~F} / \pi \mathrm{dl} ;$

where $\mathrm{F}$ is the fracture load, and $\mathrm{d}$ and $\mathrm{l}$ are the diameter and the length of the specimen in millimeters, respectively.

\section{Knoop microhardness (KH)}

Specimens $(n=5)$ of each group were prepared using the same split steel mold used for the DTS test. Cement manipulation, insertion in the mold and clamp, storage and excess removal were carried out as before.

Specimens were then removed from the molds and stored in distilled water at $37^{\circ} \mathrm{C}$ for 7 days. Before testing, they were each embedded in acrylic resin and the exposed surface was wet-ground with 1200-grit silicon carbide paper at room temperature.
The specimen's KH was determined using a KH tester (HMV 2000, Shimadzu Corporation, Tokyo, Japan) with a diamond indenter at $25 \mathrm{~g}$ load and 30 seconds dwell time. ${ }^{8,9,10}$ Three measurements were carried out on the surface of each specimen for the 18 material groups investigated.

\section{Flexural strength (FS)}

Specimens $(n=5)$ of each group were prepared using a split steel mold with internal dimensions of $25 \mathrm{~mm} \times 2 \mathrm{~mm} \times 2 \mathrm{~mm}$ diameter. ${ }^{11}$ Cement manipulation, insertion in the mold and clamp, storage and excess removal was carried out according to the previous description.

After storage in distilled water at $37^{\circ} \mathrm{C}$ for 23 hours, specimens of each group were subjected to the FS test in the same universal testing machine described before, at $0.75 \mathrm{~mm} / \mathrm{min}$ speed perpendicular to the specimen's axis until fracture occurred. ${ }^{11}$ The maximum force applied in $\mathrm{N}$, was used to calculate the flexural strength in $\mathrm{MPa}$, using the equation:

$$
\sigma=\frac{3 F L}{2 b h^{2}} \text {; }
$$

where $\sigma$ is the flexural strength in $\mathrm{MPa} ; \mathrm{F}$ is the maximum force in Newtons, exerted on the specimen; $\mathrm{L}$ is the distance in millimeters, between the supports, accurate to $0.01 \mathrm{~mm}$; b is the width in millimeters, at the center of the specimen measured prior to testing; $\mathrm{h}$ is the height in millimeters, at the center of the specimen measured prior to testing.

The standard for flexural strength measurement (ISO 9917-2:2010) ${ }^{11}$ require five specimens for each material. It is suggested to compare the values of flexural strength with the limit value specified $(25 \mathrm{MPa})$. If four or five results are not less than the minimum value, the material passes the test. If two or fewer results satisfy the limit value, the material fails the test. If three specimens satisfy the limit value, it will necessary to prepare and test five further specimens. All five results in the second series shall comply with the limit value specified for restorative GIC.

\section{Analysis of the stabilization time (ST)}

Samples of each GIC ( $n=5)$ were analyzed by Fourier Transform Infrared spectroscopy (FTIR). 
The materials were manipulated according to the manufacturers' instructions. After mixing, the material was kept between polyester tapes at ambient controlled temperature $\left(25^{\circ} \mathrm{C}\right)$ to protect it from desiccation, and interposed between two plates of glass and loaded with a force of $0.4 \mathrm{~N}$ for 30 seconds to standardize the thickness of the material. After 5 min of curing, samples of GIC were prepared for measurements. ${ }^{6}$

The measures were done using the Vertex $70 \mathrm{v}$ Fourier Transform InfraRed spectrometer (Bruker ${ }^{\circledR}$, Massachusets, USA), with $4 \mathrm{~cm}^{-1}$ of resolution with average of 128 scans and the spectral range of $4000-400 \mathrm{~cm}^{-1}$. The FTIR spectra was collected every $10 \mathrm{~min}$ for $120 \mathrm{~min}^{6}{ }^{6}$ A mathematical function was adopted to obtain the characteristic time $(\tau){ }^{6}$ using the Origin software (OriginPro 9 Corporation, Northampton, US).

For stabilization time analysis no repetitions are necessary since FTIR spectroscopy provides the vibrational modes of the molecules, evaluated by the optical absorption bands of the sample, which are considered fingerprints of specific molecules, allowing to obtain precise information about chemical changes in the material, the latter being assessed based on the possible changes in absorption bands and/or appearance of new bands. ${ }^{6}$

\section{Statistical analysis}

Data had a normal distribution and homogeneity of variance (Shapiro Wilk and Levene test with $\mathrm{p}>5 \%$ ) and were analyzed with ANOVA and the Tukey test $(\mathrm{p}<0.05)$. The Spearman Rank Correlation test $(p<0.05)$ was used to test the dependence between the mechanical properties and stabilization time results.

All statistical analysis were carried out in SPSS (IBM Statistics, Armonk, USA).

\section{Results}

\section{Compressive strength}

The results for CS are presented in Figure 1A. The highest CS values were registered for EF, GL9, $\mathrm{GI}$ and $\mathrm{KM}$. The lowest CS values were registered for B, MG, VF and IM. The other materials presented intermediate values. According to ISO 9917-1:2007,7 the CS of a glass-ionomer cement should not be lower than $100 \mathrm{MPa}$. Considering this reference, the cements IG, MA, IM, VF, MG and B did not achieve the minimum CS value determined by the ISO standard. GICs with lower powder/liquid ratio (<2.0:1) had the lowest values of CS, except IM and MG.

\section{Diametral tensile strength}

The results for DTS are presented in Figure 1B. The highest DTS values were registered for $\mathrm{V}, \mathrm{KM}, \mathrm{CR}$, GL2, EF, GI, R, GL9, and IZ. The lowest DTS values were registered for groups IG, MA, B, and MG. The other groups presented intermediate values.

\section{Knoop mcrohardness}

Means and standard deviations obtained for $\mathrm{KH}$ are shown in Figure 2. The KH for EF was statistically different and superior to other materials tested $(p<0.05)$. KH values for human enamel is $343 \pm 23$ and for dentin is $68 \pm 3 .{ }^{12}$ Using these, the cements $\mathrm{EF}$, GL2, GI, and GL9 achieved KH values compatible to enamel's KH. The materials IG and VF reached KH values compatible with dentin's KH. However, B, IM, MA, and MG presented KH values lower than the usual $\mathrm{KH}$ expected for dentin.

\section{Flexural strength}

The results for FS are presented in Figure 3. According to ISO 9917-2:2010"11, the minimum parameter is $25 \mathrm{MPa}$. The higher FS values were registered for GL2, EF, GL9 and IS, and they were the only groups that corresponded to the ISO's cut off point.

\section{Stabilization time}

The time in minutes of the stabilization process of the GICs are presented in Table 2. Stabilization time is five times the value of $\tau$, which represents approximately $99 \%$ of the variation of the measure, according to the behavior of an exponential function. ${ }^{6}$ There are some significant differences in ST among the GICs tested $(p<0.05)$. The highest ST was found for the GL2 and the lowest for B. The exponential profiles of the spectra of 3 different GICs tested as a function of time are presented in Figure 4.

Table 3 presents ranking of the mechanical test results based on CS values. Using the Spearman Rank Correlation test to correlate the ST numbers for 

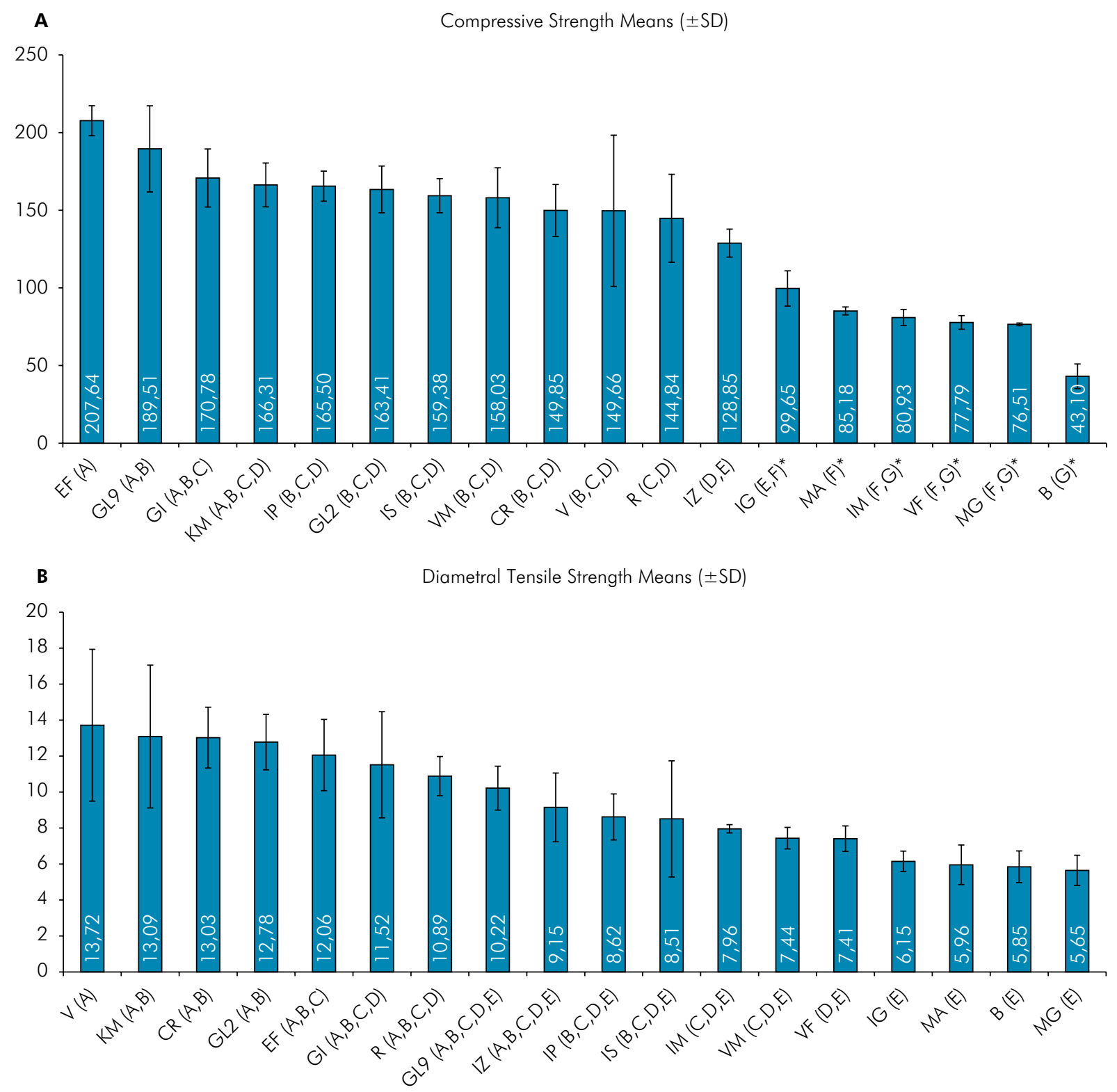

Figure 1. Means and standard deviations for compressive strength (A) and diametral tensile strength (B) of 18 different GICs. Bars with the same letters under them present no statistical difference $(p>0.05)$. Results marked with a $\left(^{*}\right)$ did not achieve the minimum cut off point that was established by ISO.

the 18 materials with each material's rank, based on the mean rank for all mechanical strength values, an $r$ value of $0.63(p=0.04)$ was found. ST correlated positively with mechanical properties, except for VF that had a long ST value but was a very weak material; and $\mathrm{KM}$, which was a strong material but had a short ST value. This relates to the general observation that cements with slow-stabilization chemical bonds are generally superior in mechanical properties.

\section{Discussion}

The null hypotheses were rejected once there was difference among GICs in terms of their mechanical properties tested and there was a positive correlation between stabilization time of GIC chemical bonds and the mechanical properties of eighteen GICs tested.

The data obtained by FTIR give information about the chemical interactions that occur in the material 


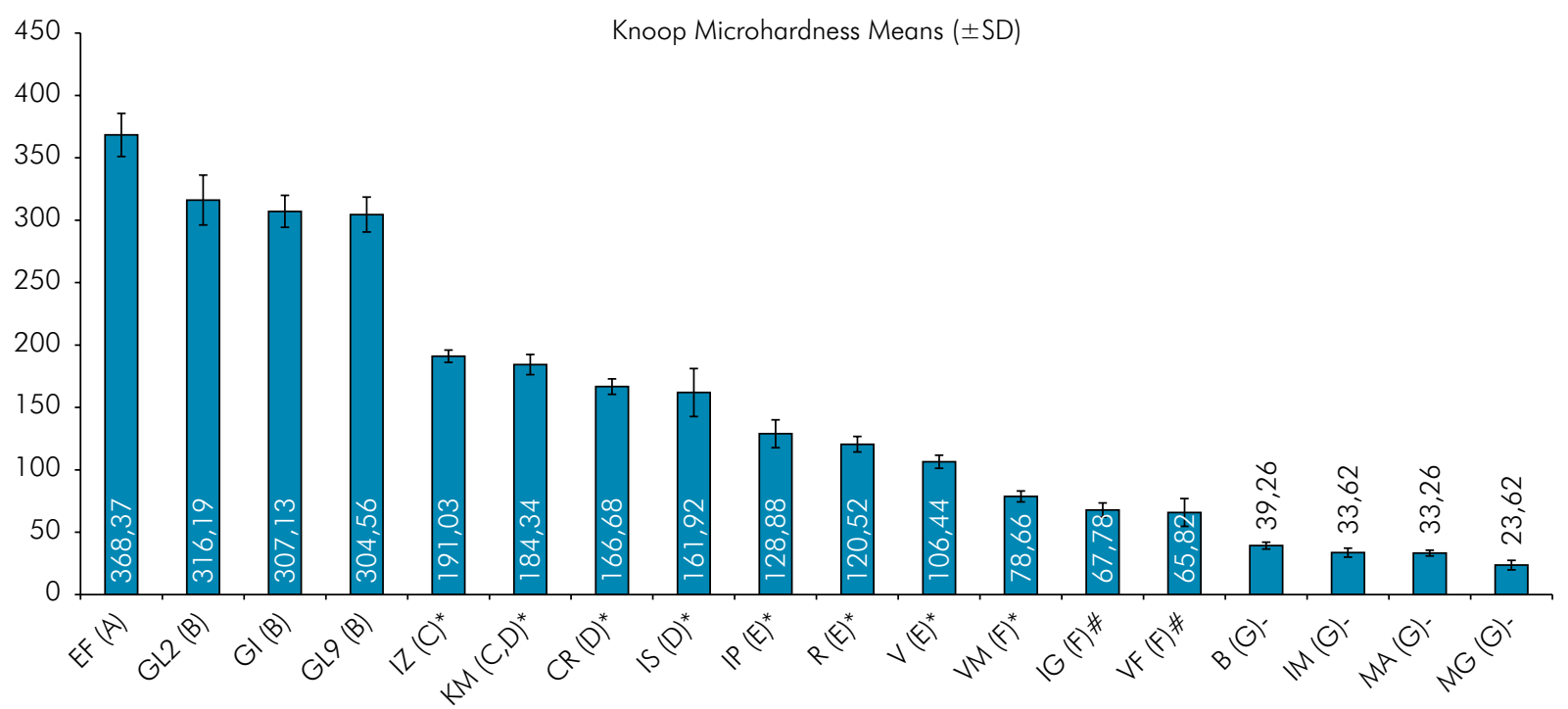

Figure 2. Means and standard deviations for $\mathrm{KH}$ of 18 different GICs. Bars with the same letters under them present no statistical difference $(p>0.05)$. Groups with no marks presented KH similar to enamel' hardness; groups marked with $\left(^{*}\right)$ presented $\mathrm{KH}$ intermediate between enamel and dentin values; groups marked with (\#) presented $\mathrm{KH}$ similar to dentin hardness, and groups marked with (-) did not approach the minimum dentin hardness.

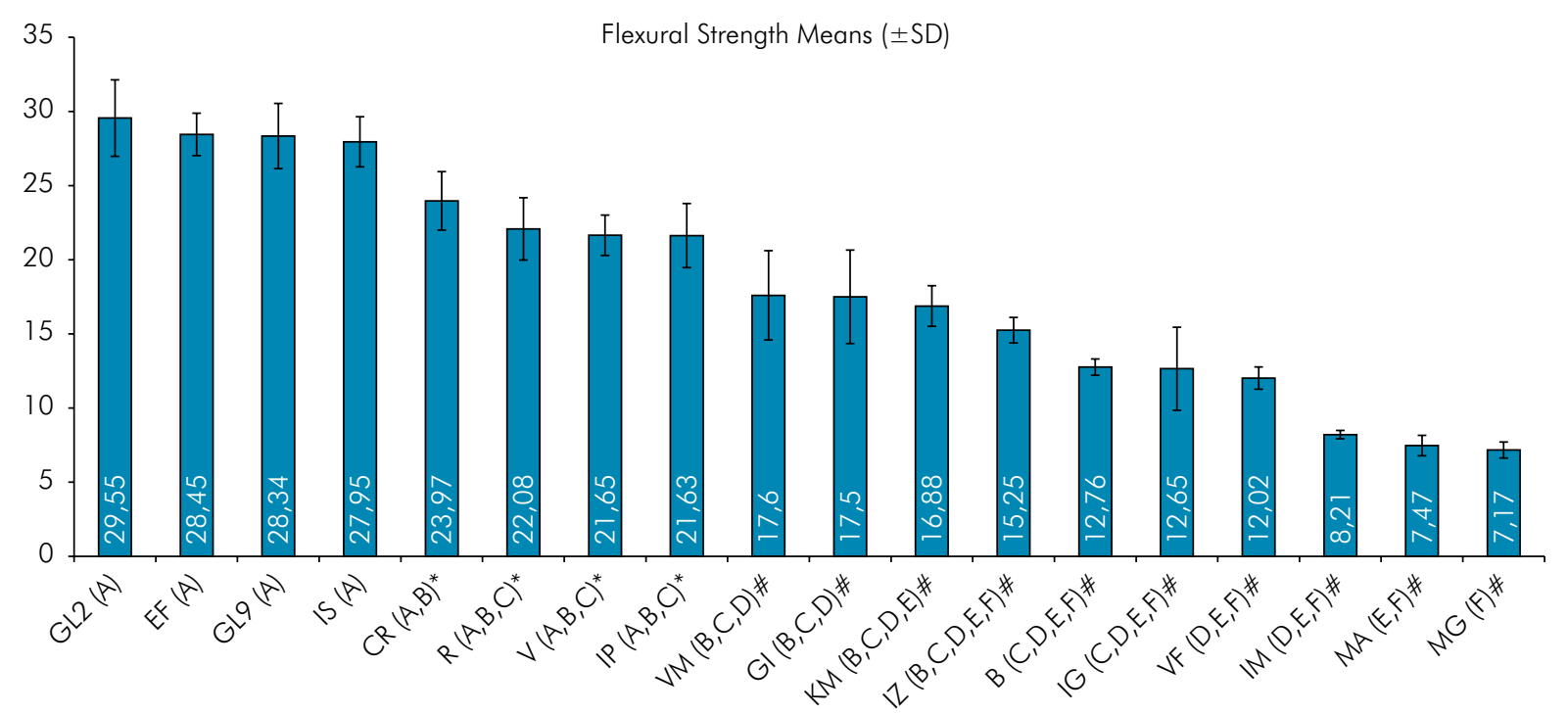

Figure 3. Means and standard deviations for FS of 18 different GICs. Bars with the same letters under them present no statistical difference $(p>0.05)$. Groups marked with $(*)$ did not reach the cutoff point, but are not statistically different from the brands above it; groups marked with (\#) did not achieve the minimum cut off point established and were statistically different from other groups

during its setting reaction ${ }^{13}$ and allows to evaluate the chemical bonds ST of the GICs. After a rapid initial hardening reaction, the GICs continue to undergo changes for some time evident by the increase in mechanical properties of the cement with aging time. ${ }^{14}$ The calcium polyacrylate, tends to increase as
GIC powder is increased. ${ }^{6}$ It shows that a chemical reaction has occurred and chemical bonds have been established. Also, the authors ${ }^{6}$ proposed to analyze the dynamics of GIC setting mechanism based on the time intervals required for the GIC to achieve stability. For the KM, the ST takes up to 150 minutes, 
- Correlation between mechanical properties and stabilization time of chemical bonds in glass-ionomer cements

Table 2. Means and standard deviations of the time required to stabilize the chemical reactions of the GICs.

\begin{tabular}{lccc}
\hline \multirow{2}{*}{ Groups } & \multicolumn{3}{c}{ Time in minutes } \\
\cline { 2 - 4 } GL2 & \multicolumn{1}{c}{ Stabilization time $(\mathrm{ST})(5 \times \tau)$} & Setting time according to the manufacturer \\
GI & $41(4) \mathrm{AB}$ & 240 & $5 \mathrm{~min} 30 \mathrm{sec}$ \\
GL9 & $40.9(3.7) \mathrm{ABC}$ & 205 & $3 \mathrm{~min} 15 \mathrm{sec}$ \\
IP & $40(3) \mathrm{BC}$ & 204.5 & $2 \mathrm{~min} 20 \mathrm{sec}$ \\
VF & $39.9(2.9) \mathrm{BC}$ & 200 & $2 \mathrm{~min} 30 \mathrm{sec}$ \\
EF & $37.3(2.3) \mathrm{BCD}$ & 199.5 & $2-4 \mathrm{~min}$ \\
CR & $33(4.9) \mathrm{BCDE}$ & 186.5 & $2 \mathrm{~min}$ \\
VM & $32.9(1.2) \mathrm{BCDE}$ & 165 & $6 \mathrm{~min}$ \\
V & $32.3(1) \mathrm{CDE}$ & 164.5 & $2 \mathrm{~min} 30 \mathrm{sec}-4 \mathrm{~min}$ \\
MA & $30.4(2.2) \mathrm{DEF}$ & 161.5 & $3-4 \mathrm{~min}$ \\
IZ & $30(4.3) \mathrm{DEFG}$ & 152 & $3-4 \mathrm{~min}$ \\
IS & $29.2(1.2) \mathrm{DEFGH}$ & 150 & $2 \mathrm{~min}$ \\
R & $28.5(1.5) \mathrm{DEFGH}$ & 146 & $2 \mathrm{~min}$ \\
IG & $25.71(2) \mathrm{EFGH}$ & 142.5 & $3-4 \mathrm{~min}$ \\
IM & $25.3(4.9) \mathrm{EFGH}$ & 128.5 & $5 \mathrm{~min}$ \\
KM & $23.6(2.9) \mathrm{FGH}$ & 126.5 & $5 \mathrm{~min}$ \\
MG & $21.8(3.6) \mathrm{GH}$ & 118 & $3-5 \mathrm{~min}$ \\
B & $20.3(2.5) \mathrm{H}$ & 109 & $5-6 \mathrm{~min}$ \\
\hline
\end{tabular}

*ANOVA and Tukey's Test $(p<0.05)$; Different letters indicate statistical significance.
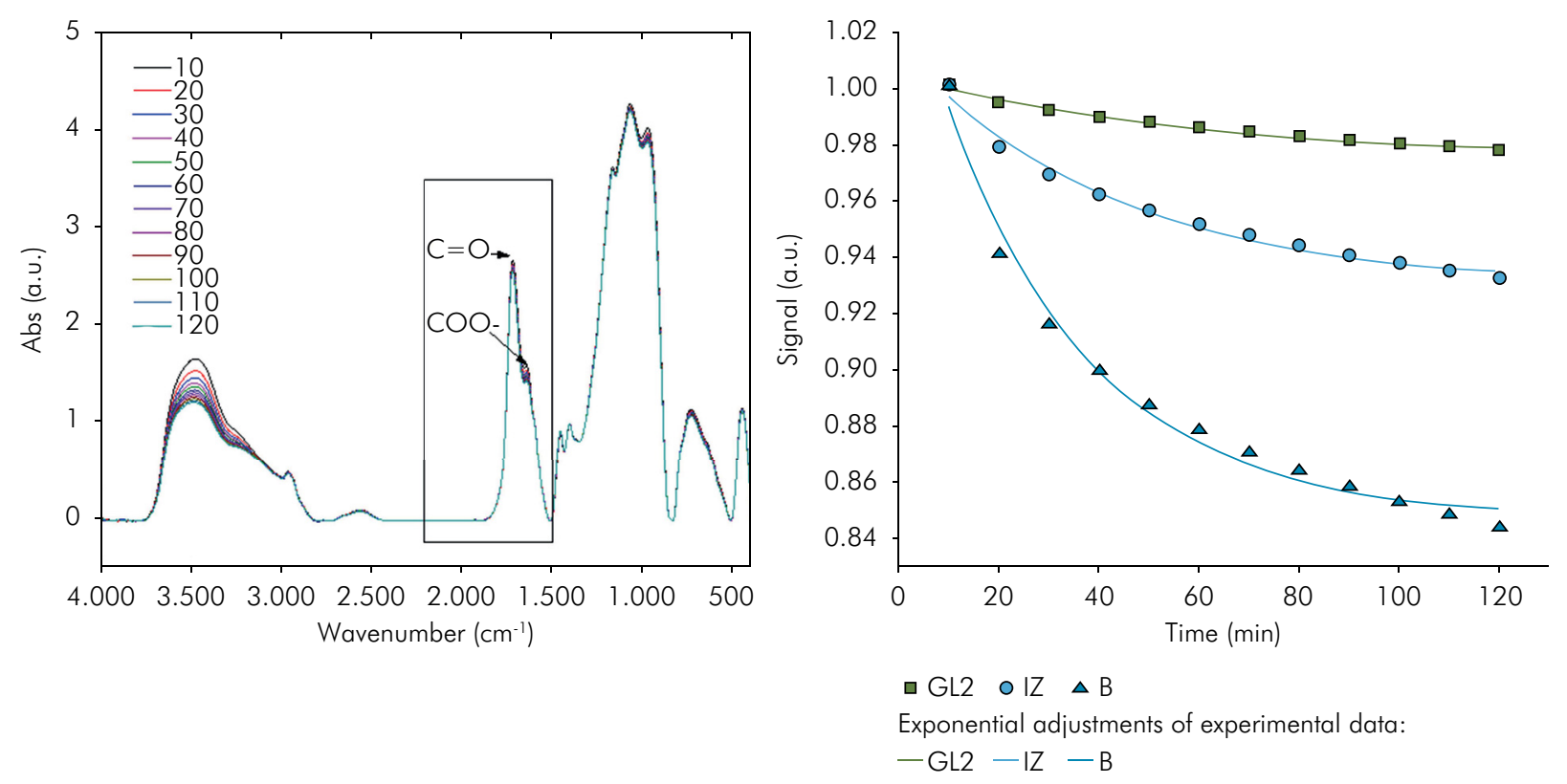

Figure 4. Fourier Transform Infrared Spectroscopy (FTIR) spectra of 3 different GICs (GL2, IZ and B) as a function of time. An exponential fitting was performed to obtain the characteristic decay time $(\tau)$ of GICs.

suggesting that during this time, the material is still in the process of maturation and therefore vulnerable to the mastication on it. $^{6}$
It is worth noting that the hardening time of a material evaluated by means of indentations tests and presented in the package by the manufacturer 
Table 3. Rank orders of mechanical test results (based on CS).

\begin{tabular}{|c|c|c|c|c|c|}
\hline Material & DTS & $\mathrm{KH}$ & FS & Mean of ranks & Rank \\
\hline EF & 5 & 1 & 2 & 2.25 & 1 \\
\hline GL9 & 8 & 4 & 3 & 4.25 & 3 \\
\hline $\mathrm{Gl}$ & 6 & 3 & 10 & 5.50 & 4 \\
\hline KM & 2 & 6 & 11 & 5.75 & 5 \\
\hline IF & 10 & 9 & 8 & 8.00 & 9 \\
\hline GL2 & 4 & 2 & 1 & 3.25 & 2 \\
\hline IS & 11 & 8 & 4 & 7.50 & 8 \\
\hline VM & 13 & 12 & 9 & 10.50 & 12 \\
\hline$C R$ & 3 & 7 & 5 & 6.00 & 6 \\
\hline V & 1 & 11 & 7 & 7.25 & 7 \\
\hline$R$ & 7 & 10 & 6 & 8.50 & 10 \\
\hline IZ & 9 & 5 & 12 & 9.50 & 11 \\
\hline IG & 15 & 13 & 14 & 13.75 & 13 \\
\hline MA & 16 & 17 & 17 & 16.00 & 17 \\
\hline IM & 12 & 16 & 16 & 14.75 & 14 \\
\hline VF & 14 & 14 & 15 & 14.75 & 15 \\
\hline$M G$ & 18 & 18 & 18 & 17.75 & 18 \\
\hline B & 17 & 15 & 13 & 15.75 & 16 \\
\hline
\end{tabular}

DTS: diametral tensile strength; $\mathrm{KH}$ : knoop microhardness; FS: flexural strength.

(setting time) is different from the time to reach chemical bonds stability ('completely' reacted), which was measured by $\tau$ in the present study. From the clinical point of view, the faster the material takes hold, it will be less susceptible to fracture by early mastication on it. On the other hand, the data showed that the longer it takes for the chemical reactions to stabilize, the greater the values of mechanical strength. It is possible that the longer the GIC takes to stabilize the chemical bonds during the setting process, the greater the amount of chemical bonds responsible for the increase in the mechanical properties of the material. It would be advisable for companies manufacturing GICs to develop cements that have a fast setting time, but that take a longer time for the chemical bonds to achieve great stability.

This study demonstrated a direct correlation among the properties evaluated: the materials that presented higher CS usually presented with higher DTS, FS and KH as well. Mechanical tests have an important role as they represent a way to evaluate a material and predict its clinical performance. ${ }^{15}$

The CS test showed a large variation of results among different brands of GICs (43.1 to 207.64 MPa).
Despite this, as all materials tested are indicated for the same clinical application, it is expected that they present similar mechanical behavior. Six among the 18 GICs tested presented with values below the minimum recommended by $\mathrm{ISO}^{7}$. To explain the variations in CS observed in this study, a precise knowledge of the chemical composition of the commercial brands of GICs is necessary. ${ }^{16}$

Many studies test and compare the CS among different conventional GICs, however it is impossible to compare them due to differences in the methodological approaches of most studies reported. ${ }^{17}$ The ISO is responsible for developing and publishing international standards in order to ensure quality, safety and efficiency of products, services and systems around the globe. ${ }^{18}$ However, most researchers do not completely follow these specifications, altering some features such as the specimen's dimensions, storage and testing time. Previous authors have evaluated mechanical properties of GICs but only one of them used the standardized testing protocols established by ISO exactly to test CS, making it harder to compare results of different studies ${ }^{17}$. In addition, operator variables may affect the results, such as in cement manipulation and temperature control., ${ }^{5,19}$ For appropriate selection of a GIC in each clinical situation, it is important to compare the mechanical properties of different brands of GICs in the same study, and also to understand which of these brands adequately fulfils ISO requirements. This study stands out from the rest in the literature as it involves the greatest number of restorative GIC brands ever tested.

The DTS test was carried out because it is a test that simulates better how materials fail by crack propagation. ${ }^{20,21}$ The DTS values presented few significant statistical differences compared to other tests. VF, B, MA, and MG consistently displayed values among the 5 lowest values for both mechanical strength tests. The weakest restorative GICs showed similar or even lower values when compared to luting GICs in FS and DTS. ${ }^{16}$

Higher $\mathrm{KH}$ values may be related to different sizes and shapes of glass particles which are not equal among all brands tested..$^{10}$ Indeed, higher DTS values also correspond to smaller particles, smaller voids and more dense surface texture, as 
previously demonstrated for $\mathrm{KM}^{10}$, whose particles are around $2 \mu \mathrm{m} .{ }^{22}$ The enamel $\mathrm{KH}$ value is $343 \mathrm{KH}$ and the dentin value is $68 \mathrm{KH} .^{12}$ These references draw attention to the relatively low results of IG, VF, B, IM, MA, and MG. These did not even reach the dentin $\mathrm{KH}$ value, making their behavior in the oral environment questionable.

CS is not fundamental if tensile or shear failure show GIC fractures at the atomic level. ${ }^{23}$ Nevertheless, the ISO standard for acid-based cements, ${ }^{7}$ does not describe a standardized test for FS. However, the ISO standard for resin-modified GICs ${ }^{11}$ does describe it and may be a good method of comparison. The minimal FS required is $25 \mathrm{MPa},{ }^{11}$ and based on this, only four conventional restorative GICs fulfilled this cut off point. Unfortunately, no study in the literature followed exactly the ISO requirements, preventing any chance of comparison among outcomes. ${ }^{17}$ The DTS and KH values have been accepted for clinical application for most GICs tested in this study; the FS results point to a need for enhancement of some conventional GICs. The GICs with highest FS values were GL2, EF, GL9 and IS. FS is affected by the density of available carboxylic groups instead of the length of polymer chains. ${ }^{22}$ Thus, high FS values found in the present study for 4 materials among the 18 GICs tested may be related to appropriate polyacid concentration in their composition, apart from other factors.

Data from the present study confirms that a high $\mathrm{P} / \mathrm{L}$ ratio influences the mechanical properties. ${ }^{1}$ The variability of the $\mathrm{P} / \mathrm{L}$ ratio can be easily recognized by observing the results. Lower $\mathrm{P} / \mathrm{L}$ ratio GICs (VF, MA, IG, B), displayed poor mechanical properties. CS results of the cements almost doubled as the $\mathrm{P} / \mathrm{L}$ ratio increased from 2:1 to 3:1, again confirming this influence, except for the MG and IM materials. MG and IM have a higher P/L of 3:1 and 2.7:1 respectively, but poor mechanical properties as for other materials. In a separate visual evaluation, the liquids of both brands showed increased viscosity compared to others. This fact may be ascribed to the high polyacid concentration of IM and MG, leading to incomplete dissolution, impaired polysalts matrix formation and a weakening effect in the hardened cement. ${ }^{22,24}$
The encapsulated GICs (EF, CR and IS) presented similar results for FS but different values for CS, DTS and $\mathrm{KH}$, distributed among the medium/high values. These results show that a decrease in operator-induced variability by the use of encapsulated GICs results in good mechanical properties. ${ }^{25}$ All the results described confirm that not only mixing type may influence material properties, but also the overall effect must be defined by $\mathrm{P} / \mathrm{L}$ ratio, initial viscosity and the mixing technique. ${ }^{26}$

It is important to highlight that the results of EF in this study were the only ones with statistically significant best results for all three tests performed. The poor mechanical properties of conventional GICs did previously limit wider application, but this reality seems to be changing. Several studies demonstrated good performance of the GICs with good success rate, ${ }^{4,27,28,29}$ demonstrating the potential of high viscosity GICs materials with applications in minimally dentistry. ${ }^{27}$

The results of this study have far-ranging implications including for public services and manufacturers, as some of these materials may not withstand the clinical situations indicated in their manufacturers' instructions. However, this was a laboratory study and more clinical studies are necessary to compare these materials in function over the years. Future studies like this can be useful to validate changes in the composition of the GICs that can improve the mechanical properties and accelerate the stabilization time.

\section{Conclusion}

It can be concluded that different brands of GICs behave differently in terms of mechanical properties, especially due to variations in $\mathrm{P} / \mathrm{L}$ ratio, viscosities and manipulation techniques. It was possible to notice a correlation among the properties evaluated: the materials that presented higher CS values usually presented higher DTS, FS and KH as well. GICs with longer stabilization times of chemical bonds are generally stronger, and the ST value obtained from FTIR is useful in predicting the strength of the majority of GICs tested. 


\section{Acknowledgements}

The authors thank the Brazilianfunding agencies Finep (Financiadora de Estudose Projetos), Capes (Coordenação de Aperfeiçoamento de Pessoal de Nível Superior) and $\mathrm{CNPq}$ (Conselho Nacional de Desenvolvimento Científico e Tecnológico) for their support.

\section{References}

1. Sidhu SK, Nicholson JW. A review of glass-ionomer cements for clinical dentistry. J Funct Biomater. 2016 Jun;7(3):E16. https://doi.org/10.3390/jfb7030016

2. Nicholson JW. Chemistry of glass-ionomer cements: a review. Biomaterials. 1998 Mar;19(6):485-94. https://doi.org/10.1016/S0142-9612(97)00128-2

3. Mickenautsch S. High-viscosity glass-ionomer cements for direct posterior tooth restorations in permanent teeth: the evidence in brief. J Dent. 2016 Dec;55:121-3. https://doi.org/10.1016/i.jdent.2016.10.007

4. Gurgan S, Kutuk ZB, Ergin E, Oztas SS, Cakir FY. Clinical performance of a glass ionomer restorative system: a 6-year evaluation. Clin Oral Investig. 2017 Sep;21(7):2335-43. https://doi.org/10.1007/s00784-016-2028-4

5. Baig MS, Fleming GJ. Conventional glass-ionomer materials: A review of the developments in glass powder, polyacid liquid and the strategies of reinforcement. J Dent. 2015 Aug;43(8):897-912. https://doi.org/10.1016/i.jdent.2015.04.004

6. Yamakami SA, Ubaldini AL, Sato F, Medina Neto A, Pascotto RC, Baesso ML. Study of the chemical interaction between a high-viscosity glass ionomer cement and dentin. J Appl Oral Sci. 2018 Jul;26(0):e20170384. https://doi.org/10.1590/1678-7757-2017-0384

7. International Organization for Standardization - ISO. ISO 9917-1:2007 - Dentistry: Water based cements. Part 1: Powder/liquid acidbased cements. Geneva: International Organization for Standardization; 2007.

8. Anusavice KJ. Phillips' science of dental materials. Philadelphia: WB Saunders; 1994.

9. Associação Brasileira de Normas Técnicas - ABNT. NBR. 2011;7222:2011: Concreto e argamassa - Determinação da resistência à tração por compressão diametral de corpos de prova cilíndricos. Rio de Janeiro: Associação Brasileira de Normas Técnicas; 2011.

10. Xie D, Brantley WA, Culbertson BM, Wang G. Mechanical properties and microstructures of glass-ionomer cements. Dent Mater. 2000 Mar;16(2):129-38. https://doi.org/10.1016/S0109-5641(99)00093-7

11. International Organization for Standardization - ISO. ISO 9917-2:2010: Dentistry - Water based cements. Part 2: Resin-modified cements. Geneva: International Organization for Standardization; 2007.

12. Craig RG, Peyton FA. The micro-hardness of enamel and dentin. J Dent Res. 1958 Aug;37(4):661-8. https://doi.org/10.1177/00220345580370041301

13. Peter J. Infrared and raman spectroscopy: principles and spectral interpretation. San Diego: Elsevier; 2011.

14. Nicholson JW. Maturation processes in glass-ionomer dental cements. Acta Biomater Odontol Scand. 2018 Jul;4(1):63-71. https://doi.org/10.1080/23337931.2018.1497492

15. Wang L, D'Alpino PH, Lopes LG, Pereira JC. Mechanical properties of dental restorative materials: relative contribution of laboratory tests. J Appl Oral Sci. 2003 Sep;11(3):162-7. https://doi.org/10.1590/S1678-77572003000300002

16. Cattani-Lorente MA, Godin C, Meyer JM. Early strength of glass ionomer cements. Dent Mater. 1993 Jan;9(1):57-62. https://doi.org/10.1016/0109-5641(93)90107-2

17. Menezes-Silva R, Cabral RN, Pascotto RC, Borges AF, Martins CC, Navarro MF, et al. Mechanical and optical properties of conventional restorative glass-ionomer cements - a systematic review. J Appl Oral Sci. 2019 Feb;27:e2018357. https://doi.org/10.1590/1678-7757-2018-0357

18. International Organization for Standardization - ISO. Homepage. 2018[cited 2018 Feb 5]. Available from: https://www.iso.org

19. Ilie N, Hickel R. Mechanical behavior of glass ionomer cements as a function of loading condition and mixing procedure. Dent Mater J. 2007 Jul;26(4):526-33. https://doi.org/10.4012/dmi.26.526

20. Kerby RE, Bleiholder RF. Physical properties of stainless-steel and silver-reinforced glass-ionomer cements. J Dent Res. 1991 Oct;70(10):1358-61. https://doi.org/10.1177/00220345910700100801

21. Dowling AH, Fleming GJ, McGinley EL, Addison O. Improving the standard of the standard for glass ionomers: an alternative to the compressive fracture strength test for consideration? J Dent. 2012 Mar;40(3):189-201. https://doi.org/10.1016/i.jdent.2011.12.002

22. Guggenberger R, May R, Stefan KP. New trends in glass-ionomer chemistry. Biomaterials. 1998 Mar;19(6):479-83. https://doi.org/10.1016/S0142-9612(97)00127-0

23. Prosser HJ, Powis DR, Brant P, Wilson AD. Characterization of glass-ionomer cements. 7. The physical properties of current materials. J Dent. 1984 Sep;12(3):231-40. https://doi.org/10.1016/0300-5712(84)90067-8 
- Correlation between mechanical properties and stabilization time of chemical bonds in glass-ionomer cements

24. Wilson AD, Crisp S, Abel G. Characterization of glass-ionomer cements. 4. Effect of molecular weight on physical properties. J Dent. 1977 Jun;5(2):117-20. https://doi.org/10.1016/0300-5712(77)90070-7

25. Dowling AH, Fleming GJ. Is encapsulation of posterior glass-ionomer restoratives the solution to clinically induced variability introduced on mixing? Dent Mater. 2008 Jul;24(7):957-66. https://doi.org/10.1016/i.dental.2007.11.016

26. Nomoto R, McCabe JF. Effect of mixing methods on the compressive strength of glass ionomer cements. J Dent. 2001 Mar;29(3):205-10. https://doi.org/10.1016/S0300-5712(01)00010-0

27. Türkün LS, Kanik Ö. A Prospective Six-year clinical study evaluating reinforced glass ionomer cements with resin coating on posterior teeth: quo Vadis? Oper Dent. 2016 Nov/Dec;41(6):587-98. https://doi.org/10.2341/15-331-C

28. Grossi JA, Cabral RN, Ribeiro APD, Leal SC. Glass hybrid restorations as an alternative for restoring hypomineralized molars in the ART model. BMC Oral Health. 2018(1):18:65. https://doi.org/10.1186/s12903-018-0528-0

29. Hilgert LA, Amorim RG, Leal SC, Mulder J, Creugers NH, Frencken JE. Is high-viscosity glass-ionomer-cement a successor to amalgam for treating primary molars? Dent Mater. 2014 Oct;30(10):1172-8. https://doi.org/10.1016/i.dental.2014.07.010 